\title{
Coronary artery spasm: A quandary
}

Ngow HAa, Wan Khairina WMN b

a Kulliyyah of Medicine, International Islamic University Malaysia

b Hospital Tengku Ampuan Afzan, Kuantan, Pahang, Malaysia

\begin{abstract}
Coronary artery spasm can result in acute coronary syndrome. This vasospastic syndrome can cause profound morbidity and mortality as a significant proportion of patients continue to have angina despite optimal medical therapy. We illustrate the dilemma in managing a young woman who presented with non ST-segment myocardial infarction as a result of it. She did not have the conventional risks for coronary artery disease except the family history of myocardial infarction. Vasospasm was demonstrated at the mid right coronary artery which resolved with intracoronary nitroglycerine during angiogram. Most women with no significant heart disease following demonstration of normal or "near normal" coronary arteries after angiography are offered no treatment beyond reassurance each year. New data suggest that this approach may no longer be appropriate and the prognosis in such patient is not as benign as previously thought. We discuss the management dilemma of such patient with associated mild atherosclerotic plaque.
\end{abstract}

KEYWORDS: Coronary vasospasm, Myocardial infarction, Non-atherosclerosis, Acute coronary syndrome.

\section{INTRODUCTION}

A novel heart syndrome mimicking atherosclerotic myocardial infarction, coronary artery spasm was initially described by Prinzmetal in $1959 .{ }^{1}$ It was first illustrated as a variant form of angina which predominantly occurred at rest and usually associated with transient ST-segment elevation myocardial infarction on the electrocardiogram. The angina resulted from occlusive or sub-occlusive epicardial coronary artery that underwent spasm. ${ }^{2}$ This vasospastic mechanism was thought to originate at the site of an atherosclerotic plaque. ${ }^{3}$ Therapy for vasospastic coronary artery can be difficult; many patients continue to have angina despite optimally treated with nitrates and calcium channel blocker. These episodes can be detrimental and occasionally life-threatening when myocardial infarction or arrhythmias occur. We describe a young woman who presented with non ST-segment myocardial infarction (NSTEMI) and coronary spasm was demonstrated during angiography. The management of such patient remained a debate with absence of hard scientific evidences and guidelines.

\section{CASE REPORT}

A 39-year-old Indian female presented with severe, prolonged angina that was relieved by sublingual nitroglycerine. She had experienced exertional angina for 1 month. There was no associated dyspnoea, sweating or palpitation. She had no conventional risk

\section{Corresponding author}

Dr Harris A Ngow

Department of Internal Medicine

Kulliyyah of Medicine

International Islamic University Malaysia

P.O.Box 141

Kuantan, Pahang Darul Makmur

Malaysia

Email: harrisngow@gmail.com factor for coronary artery disease. Her body mass index (BMI) was $32 \mathrm{~kg} / \mathrm{m}^{2}$. She was not on weight reduction medication. Physical examination was unremarkable. Electrocardiogram showed deep inverted T wave in inferior leads. Creatinine kinase was $237 \mathrm{U} / \mathrm{L}$ and Troponin $\mathrm{T}$ was $0.52 \mathrm{ug} / \mathrm{L}$. A diagnosis of NSTEMI was made. Her low density lipoprotein and triglycerides were high. She was treated with dual-antiplatelet, enoxaparine, statin and anti-anginal drugs. Echocardiography showed preserved LVEF (ejection fraction $=63 \%$ ) without wall motion abnormality. Coronary angiography showed no evidence of severe stenosis (Figure 1).

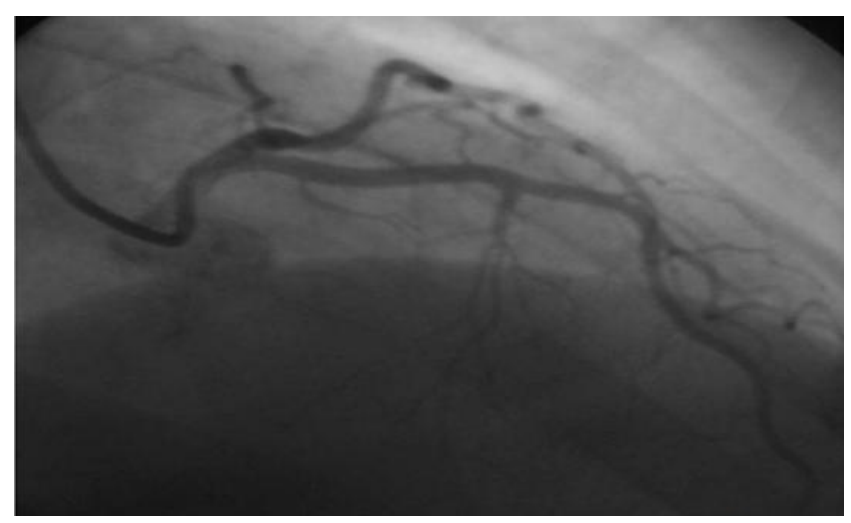

Figure 1. This angiogram shows the normal left coronary system.

Vasospasm was demonstrated at the mid right coronary artery which resolved with intracoronary nitroglycerine during coronary angiogram. A mild focal atherosclerotic plaque was seen proximal to it (Figure $2 \mathrm{a}$ and $2 \mathrm{~b})$. 


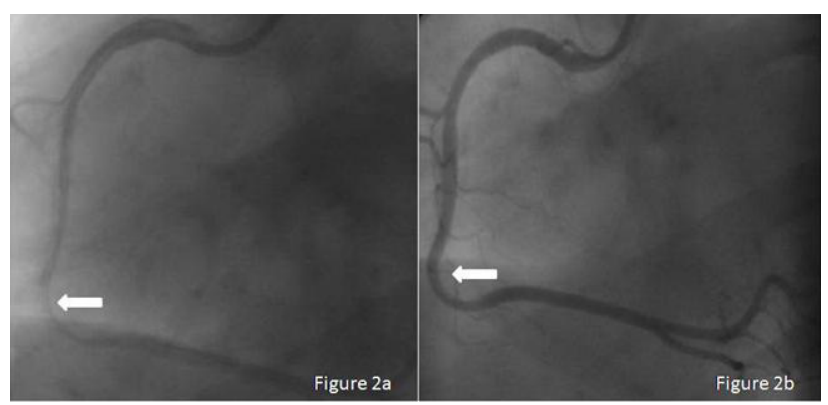

Figure 2. This angiogram showed the spasm right coronary artery which resolved with intracoronary nitroglycerine (Figure 2a). A focal atherosclerotic plaque was seen at the mid segment of right coronary artery (Figure $2 \mathrm{~b}$ ).

The NSTEMI was the result of coronary artery spasm at the atherosclerotic site. She remained well with nitrates and calcium channel blockers for the past 2 years.

\section{DISCUSSION}

Coronary spasm is a variant angina predominantly occurring at rest and usually associated with transient ST-segment elevation on the electrocardiogram. It may lead to acute coronary syndrome and arrhythmias in young adult. This vasospastic phenomenon is similar to occlusive atherosclerotic disease. There is no independent predictor of severity of vasospasm and its recurrence. It has been postulated to occur at the atherosclerotic site or intra-mural thrombus because of heightened local vascular reactivity to potent vasoconstrictor such as thromboxane A2, serotonin and thrombin. ${ }^{4}$ Other possible mechanisms include failure of endothelium-dependent vasodilatation, increased vascular basal tone, deficiency of coronary nitric oxide production, increase in autonomic nervous activity or continuous release of vasoconstrictor cytokines by the infarct related artery. ${ }^{5}$ Nonetheless, the exact cellular mechanisms responsible for the spasm remain elusive. Other condition that can mimic myocardial infarction is Tako-Tsubo syndrome. The absence of apical ballooning with normal regional wall motion on echocardiography examination in our patient made this diagnosis less likely.

At present, there is no published registry of acute myocardial infarction with patent coronaries. There is also no well-conducted study of acute myocardial infarction secondary to coronary spasm in young adult. The diagnosis can be made by demonstration of vasospasm by provocation test like acetylcholine challenge or intravenous methylergonovine. In most case reports, the diagnosis was based on the clinical and laboratory findings without provocation. ${ }^{6} \mathrm{~A}$ recent guideline by the Japanese Circulation Society Joint Working Group advocated that the diagnosis can be solely established on clinical ground. ${ }^{7}$
The prevalence of myocardial infarction with normal coronary arteries is about $5 \% .{ }^{6}$ It is more prevalent in women (10-25\%) compared to men (6-10\%). This implies that coronary spasm is commoner in women. The reported incidence of coronary artery spasm is also higher in Asian than Caucasians. ${ }^{7}$ Coronary spasm is associated with low mortality rate $(2 \%)$, less extensive atherosclerotic artery, preserved residual left ventricular function and excellent prognosis. ${ }^{7}$ Its management remains a debate with absence of hard scientific evidences and guidelines. The therapy for vasospastic coronaries can be difficult; up to $25 \%$ of patients continue to have intractable angina despite optimal treatment. ${ }^{8}$ These episodes can be detrimental and occasionally life-threatening when myocardial infarction or arrhythmias occur.

Failing medical therapy, angioplasty is an option for coronary spasm associated with atherosclerotic disease. ${ }^{9}$ Stent implantation on vasospastic artery bears the danger of in-stent restenosis and recurrent spasm. Drug-coated stents is favourable as it is safer and limits the risk of restenosis.

\section{CONCLUSION}

The management of coronary spasm is largely anecdotal. The understanding of the mechanism and pathophysiology of coronary endothelial dysfunction may be potentially useful for the development of appropriate management strategies. Traditionally, such patients have been reassured that they do not have heart disease despite many have persistent symptoms and re-hospitalization. At present, the management approach of this difficult entity is of no difference with atherosclerotic coronary disease.

\section{REFERENCES}

1. Prizmetal M, Kennamer R, et al. Angina pec toris: A variant form of angina pectoris. Am J Med 1959; 27:375-88.

2. Meller J, Pichard A, Dack S. Coronary arte rial spasm in Prinzmetal's angina: A proved hypothesis. Am J Cardiol 1976; 37:938-40.

3. Waters DD, Miller DD, Slachcic J, et al. Fac tors influencing the long-term prognosis of treated patients with variant angina. Circu lation 1983; 68:258-65.

4. Maseri A, Davies G, Hackett D, Kaski JC. Coronary artery spasm and vasoconstric tion. The case for a distinction. Circulation 1990; 81:1983-91.

5. Kugiyama K, Yasue H, Okumura K, et al. $\mathrm{Ni}$ trix oxide activity is deficient in spasm ar teries of patients with coronary spastic an gina. Circulation 1996; 94:266-72.

6. Tun A, Khan IA. Myocardial infarction with normal coronary arteries: the pathologic and clinical perspectives. Angiology 2001; 52:299-304. 
7. Guidelines for diagnosis and treatment of patients with vasospastic angina (Coronary Spastic Angina). Circulation 2008; 72:123952.

8. Nakamura M, Takeshita A, Nose Y. Clini cal characteristics associated with with myocardial infarction, arrhythmias and sud den death in patients with vasospastic an gina. Ciculation 1987; 75:1110-6.

9. Gaspardone A, Tomai F, Versaci F, et al. Coronary artery stent placement in pa tients with variant angina refractory to medical treatment. Am J Cardiol 1999; 84:96-8. 